\title{
18 \\ MEMORY AS MENTAL TIME TRAVEL
}

\author{
Denis Perrin and Kourken Michaelian
}

\section{Introduction: continuism and discontinuism about mental time travel}

When Tulving (1972) first introduced the term, he defined episodic memory essentially as a specialized store devoted to information about the 'what', 'when', and 'where' of experienced past events. Episodic memory thus contrasted both with nondeclarative memory, devoted in part to skills and habits, and, within the category of declarative memory, with semantic memory, devoted to general facts. This definition was broadly compatible with traditional analyses of what philosophers had referred to as recollective, experiential, or personal memory (Brewer 1996), including the popular causal theory (Martin and Deutscher 1966; Bernecker 2010). But semantic memory, too, is capable of storing information about the what, when, and where of events, and accumulating evidence of a tight relationship between the ability to remember the past and the ability to imagine the future subsequently led most psychologists (including Tulving 2002) to redefine episodic memory as a form of mental time travel (MTT) in which the subject imaginatively re-experiences past events, just as, in future-oriented mental time travel (FMTT) he imaginatively 'pre-experiences' future events (Michaelian et al. 2016; De Brigard, Chapter 10, this volume). It is unclear whether this new definition of episodic memory as mental time travel is compatible with traditional philosophical analyses, which assume that there is a deep difference between remembering the past and imagining the future. Empirical research within the MTT framework has revealed a wealth of commonalities between episodic memory and FMTT, leaving no doubt that there is some sort of tight relationship between them. But is it really the case, as the framework suggests, that the only important difference between episodic memory and FMTT is constituted by their distinct temporal orientations?

Those to whom we will refer as continuists answer this question in the affirmative, maintaining that, aside from their distinct temporal orientations, there is no fundamental difference between episodic memory and FMTT - that there is a single general faculty of mental time travel (Suddendorf and Corballis 2007). Those to whom we will refer as discontinuists answer in the negative, arguing that '[episodic memories] of past events and [episodic imaginations] of future events are ultimately mental occurrences of two different kinds' (Debus 2014). ${ }^{1}$ The debate between continuists and discontinuists is ongoing, and this chapter will not attempt to settle it. The aim of the chapter is, more modestly, to survey the evidence and arguments to 
which continuists and discontinuists have appealed. Section 2 describes plausible versions of continuism and discontinuism. Sections 3 and 4 provide a brief overview of the psychological evidence for each view. Section 5 provides a more detailed review of philosophical arguments for discontinuism, and Section 6 sets out continuist critiques of those arguments. Finally, Section 7 discusses one promising discontinuist response to continuist critiques.

\section{Varieties of continuism and discontinuism}

A degree of conceptual ambiguity is an inevitable feature of any new theoretical framework, and it has not always been clear exactly what is at stake in debates over the continuity or discontinuity of episodic memory and FMTT (Klein 2016). It is crucial, in particular, for parties to the debate to be explicit about whether they hold episodic memory and FMTT to be different/the same in kind or merely in degree. An extreme continuist, for example, might maintain that their distinct temporal orientations constitute literally the only difference between episodic memory and FMTT, but there is also room for a view which acknowledges the existence of differences of degree while insisting that episodic memory and FMTT are the same in kind. Thus (anticipating some of the evidence reviewed in Section 4 below) a moderate continuist might grant, for example, that imagining future events is somewhat more cognitively effortful than remembering past events and that it involves a correspondingly stronger activation of certain brain regions, but argue that what is at issue in both remembering the past and imagining the future is nevertheless a single process, carried out by a single system. In light of the evidence for differences of degree between episodic memory and FMTT, most continuists endorse something like this moderate view.

Extreme and moderate forms of discontinuism are likewise available. An extreme discontinuist would maintain that episodic memory and FMTT have nothing at all in common with each other, but there is also room for a view which acknowledges the existence of similarities of degree while insisting that episodic memory and FMTT are different in kind. Thus (anticipating the evidence reviewed in Section 3), a moderate discontinuist might grant that episodic memory and FMTT involve constructive episodic simulation of events and that constructive episodic simulation, in turn, depends on the brain's core network but argue that the necessity of a causal link with past experience underwrites a difference in kind between the process of remembering the past and that of imagining the future.

In light of the evidence for quantitative similarities between episodic memory and FMTT, most discontinuists endorse something like this moderate view. But the fact that both continuists and discontinuists agree that there are some similarities and some differences between episodic memory and FMTT should not lead us to underestimate the extent of the disagreement between them: for the latter, there is a difference in kind between what we do when we remember the past and what we do when we imagine the future; for the former, there is only a difference of degree.

\section{Empirical evidence for continuism}

A detailed review of the empirical evidence for each of these views would be out of place here, but this section will review some of the highlights of the evidence for continuism, and the following section will do the same thing for discontinuism. ${ }^{2}$

Perhaps the most impressive evidence for continuism comes from imaging studies, which have demonstrated that strongly overlapping regions of the brain are involved in both 
episodic memory and FMTT, supporting the claim that a core (or default) network, whose major components include medial prefrontal regions, posterior regions in the medial and lateral parietal cortex, the lateral temporal cortex and the medial temporal lobe, constitutes the neural basis for both forms of MTT (Addis et al. 2007; Schacter et al. 2007). This claim, in turn, aligns with the constructive episodic simulation hypothesis (Schacter and Addis 2007a, b), which, in a refinement of Bartlett's insights on the constructive character of remembering (Bartlett 1932; Wagoner 2016), sees both remembering the past and imagining the future as products of a constructive, simulational process in which traces of disparate past experiences are linked together into coherent representations of particular events, the difference between them being simply that, in FMTT, the process simulates possible future events, whereas, in episodic memory, it simulates past events. While there is debate about how, exactly, to characterize the process in question, ${ }^{3}$ the constructive episodic simulation hypothesis comes close to capturing the dominant view among psychologists and neuroscientists on the relationship between episodic memory and FMTT.

Imaging evidence is reinforced by evidence from a variety of other sources. Studies of MTT in memory-impaired patients have found that deficits in the ability to remember one's past are strongly correlated with deficits in the ability to imagine one's future (e.g. Klein et al. 2002; Rosenbaum et al. 2005; Hassabis et al. 2007). Similarly, patients suffering from depression display parallel tendencies to remember the past and to imagine the future in overly general ways (Williams et al. 1996), and the capacities to remember past episodes and to imagine future episodes emerge in development at roughly the same age (Suddendorf and Busby 2005; Atance 2008; Perner et al. 2010; Suddendorf 2010; Viard et al. 2012). Further support for continuism comes from studies of phenomenological similarities between episodic memory and FMTT. Level of detail and intensity of experience vary with temporal distance in a similar manner in both forms of MTT (D'Argembeau and Van der Linden 2004, 2006; D'Argembeau et al. 2011; Addis et al. 2011; Schacter et al. 2012), in line with Tulving's (1985) claim that the same phenomenology continuism comes from studies of phenomenological similarities between episodic memory and FMTT. Level of detail and intensity of experience vary with temporal distance. And studies of autobiographical memory have found that episodic memory and FMTT are organized in a similar fashion, in the sense that autobiographical memories and autobiographical future events are embedded in the same narrative structures (Rathbone et al. 2011).

\section{Empirical evidence for discontinuism}

Psychology and neuroscience have thus provided persuasive evidence for continuism. But they have also provided evidence for discontinuism, and, after an initial wave of enthusiasm for extreme forms of continuism, there has been a tendency to adopt more qualified views (Schacter et al. 2012). Remembered past events, for example, are associated with richer and more vivid sensory and contextual detail than imagined future events (D'Argembeau and Van der Linden 2004, 2006; Addis et al. 2010) or imagined past events (Addis et al. 2010; De Brigard and Giovanello 2012), and the emotional valence of remembered and imagined episodes displays a similar discrepancy, with imagined future events being characterized by a greater positivity bias than remembered past events (Berntsen and Bohn 2010; Rasmussen and Bertsen 2013). Perhaps this evidence of phenomenological discrepancies only suggests a difference of degree between episodic memory and FMTT, but other evidence seems to suggest a difference in kind. Imaging studies have revealed that imagining is more cognitively demanding than remembering and in fact draws on brain regions that are not solicited by remembering (D'Argembeau and Van der Linden 2004; Schacter and Addis 2007a; Addis et al. 2007; Szpunar et al. 2007; McDonough 
and Gallo 2010; Martin et al. 2011), and there is evidence that impairments of certain brain regions affect FMTT but not episodic memory (Berryhill et al. 2010). Indeed, some researchers have even argued that two subsystems can be distinguished within the core network, with only episodic memory requiring reactivation of regions involved in the original processing of remembered information (Addis et al. 2009), and others have argued that imagining future events, in contrast to remembering past events, relies on conceptual knowledge to provide a scaffolding for the integration of episodic details (Irish et al. 2012; Duval et al. 2012); consequently, FMTT may be more schema-driven than episodic memory (Szpunar 2010; Irish et al. 2012; Duval et al. 2012; Rasmussen and Berntsen 2013; Klein and Steindam 2016).

Further support for discontinuism is provided by functional considerations. Remembering and imagining may have different functions with respect to the self, emotion, and behaviour regulation (Shao et al. 2010; Rasmussen and Berntsen 2013). For instance, an increased positivity bias for imagined future relative to remembered past events has been documented and it has been proposed this would show that episodic memory is more devoted to problem solving and behaviour regulation, while FMTT is more dedicated to securing positive self-image, regulating emotions and prompting us to approach novelty. And the constructive episodic simulation hypothesis itself suggests that episodic memory has the function of storing information which is then recombined in FMTT, thus assigning a distinctive functional role to memory. Against this view, continuists have argued that, while episodic memory indeed has this function, it performs the function with respect to the process of FMTT and the process of episodic remembering alike, both of which involve the recombination of stored information (Michaelian 2016a). But it may be possible to distinguish between a process of recombination, at work in imagining the future, and a process of recapitulation, at work in remembering the past (Addis et al. 2009; Storm and Jobe 2012), in which case there might still turn out to be a functional difference between FMTT and episodic memory.

\section{Philosophical arguments for discontinuism}

Given that there is empirical evidence for both continuities and discontinuities between episodic memory and FMTT, such evidence is unlikely to settle the debate between continuists and discontinuists. It is not immediately clear, for example, whether continuism is incompatible with the existence of distinct subsystems for episodic memory and FMTT within the core network, nor is it clear whether recombination and recapitulation amount to qualitatively different functions. Conceptual considerations thus take centre stage, allowing philosophical arguments to play a potentially decisive role in the debate. This section and the next review the main arguments that have been advanced so far, focusing in turn on epistemological, metaphysical, and phenomenological considerations.

Beginning with epistemology, one argument for discontinuism turns on the possibility or impossibility of error through misidentification in episodic memory and FMTT (Perrin 2016). On the one hand, when one episodically remembers, it is arguably possible for one to mistake an individual (object or person) figuring in the remembered episode for a similar but distinct individual, since the identity of the remembered individual is determined by one's past causal interactions with it. In other words, one can misidentify a remembered individual - episodic memory is not immune to error through misidentification. ${ }^{4}$ On the other hand, when one engages in FMTT, it is arguably impossible for one to mistake an individual figuring in the imagined episode for another individual, since the identity of the imagined individual is in effect stipulated by the imagining subject. In other words, one cannot misidentify an imagined individual - FMTT is immune to error through misidentification. 
Turning to metaphysics, another argument for discontinuism concerns the nature of the mental contents involved in remembering the past and imagining the future. Intuitively, episodic memory provides the subject with a form of direct contact with past events. According to relationalists about the objects of memory (e.g. Campbell 2002; Debus 2008, 2013, 2014; cf. Recanati 1993, 2007; Perrin 2016), when a subject episodically remembers an event, the remembered event literally constitutes part of the content of his memory. Consequently, the event must play a role in the individuation of the memory content. In this sense, episodic memory is 'world-involving'. When a subject imagines the future, however, the imagined event cannot play a role in the individuation of content, since, in order for an event to constitute part of the content of a mental state, it must be actual, not merely possible. Thus FMTT is not world-involving.

A related but distinct metaphysical argument concerns the particularity of the objects of MTT. Episodic memory seems to involve thinking about particular events with which one is acquainted through experience. FMTT, in contrast, seems to involve thinking about general types of events. For example, some have suggested that we imagine future events by thinking of general types of events and mentally projecting them forwards in time (Martin 2001; Campbell 2002; Debus 2008, 2014). While this argument is distinct from the previous argument, the generality-particularity discrepancy may stem from the possibility-actuality discrepancy, assuming that only actual events can be particular (Debus 2014).

A final metaphysical argument, or rather a pair of arguments, concerns the role of causation in episodic memory and FMTT. One argument maintains that episodic memory requires an appropriate causal link with the remembered experience, in contrast to FMTT, which obviously cannot require an analogous link (Perrin 2016). Consider a case of 'quasi-memory' in which the identity of the subject whose experiences are 'remembered' does not coincide with the identity of the subject who 'remembers' the experiences. In such a case, the 'remembering' subject is arguably not remembering at all, but merely imagining. When a subject imagines the future, in contrast, he would seem to be engaged in the same process regardless of whether he imagines his own experience or that of another subject. Another argument maintains that episodic memory and FMTT involve different kinds of awareness of potential causal links (Debus 2016). When one imagines a future event, one is arguably aware of the fact that it is causally open, in the sense that someone-perhaps oneself-might intervene to bring about or prevent the occurrence of the event. When one imagines a past event, however, one has no such awareness.

Further arguments for discontinuism point to apparent qualitative phenomenological differences between episodic memory and FMTT. One such argument claims that episodic memory alone involves experiential awareness (Debus 2014; cf. Martin 2001; Campbell 2002). This claim is related to the point concerning the actuality of the objects of episodic memory noted above. In order for someone to be experientially aware of an event, the event must presumably be actual; in other words, one cannot be experientially aware of merely possible events. Thus episodic memory, which concerns actual events, may involve experiential awareness, but FMTT, which concerns possible events, cannot.

A distinct phenomenological argument claims that autonoetic consciousness arises in a different manner in episodic memory and FMTT (Klein 2016; Perrin 2016). In episodic memory, awareness that the remembered event 'belongs' to oneself seems to arise in a prereflective manner. In FMTT, in contrast, it seems to be the result of a deliberate, inferential process. Indeed, while some have taken autonoesis to be a necessary feature of FMTT, others have argued that a simulated future experience remains essentially unaltered when the identity of the imagined 
subject shifts from the identity of the imagining subject to that of another subject. If this is right, autonoetic consciousness, which concerns the self, turns out not to be a necessary feature of FMTT, strengthening the contrast between FMTT and episodic memory (Perrin 2016).

\section{Philosophical arguments for continuism}

These arguments for discontinuism fit well with traditional philosophical analyses of remembering, one of the main goals of which has been to provide criteria for demarcating remembering from imagining. The causal theory, in particular, presupposes that there is a difference in kind between remembering the past and imagining it and maintains that this difference is to be understood in terms of the presence or absence of an appropriate causal link with the represented event. What makes the difference between remembering a past event and imagining it, according to the theory, is that the former involves an appropriate causal link with the represented event, while the latter does not. According to standard versions of the causal theory, what makes a causal link appropriate, in the relevant sense, is that it is sustained by the preservation of traces of the subject's original experience of the event.

The presupposition that there is a difference in kind between remembering the past and imagining it is threatened by the MTT framework, and some philosophers have argued that it should be abandoned entirely. MTT research suggests that the boundary between remembering the past and imagining it may be blurry (Shanton and Goldman 2010) and perhaps even that there is no boundary at all (Michaelian 2016b). In line with the constructive episodic simulation hypothesis, simulationist accounts of episodic memory thus reject the goal of providing criteria for demarcating remembering from imagining, instead classifying remembering as a kind of imagining. According to these accounts, there is no difference in kind between remembering the past and imagining it - to remember simply is to imagine the past.

Assuming that there is no difference in kind between imagining the past and imagining the future, simulationism entails continuism. It would be question-begging to appeal directly to simulationism in an attempt to defeat discontinuist arguments, and such an appeal would overlook the fact that MTT research has also provided evidence for discontinuism. Nevertheless, simulationism has a role to play in the debate. The empirical evidence for discontinuism is compatible with a broadly simulationist approach. The claim that distinct subsystems of the core network are involved in episodic memory and FMTT, for example, is compatible with the claim that episodic memory and FMTT are both simulational in character. And if remembering is simulational in character, it need not involve a causal link - simulation inevitably draws on traces originating in past experience, but simulation of a given past event need not draw on traces originating in experience of that particular event. Arguments for discontinuism assume that such a causal link is necessary, and the simulationist approach, by reminding us that that assumption is problematic, points to potential responses to those arguments.

As we saw above, for example, discontinuists might claim that there is an epistemological difference between episodic memory and FMTT, arguing that the latter is immune to error through misidentification, whereas the former is not. The idea is that, since FMTT is a form of imagination, the identities of the individuals figuring in the representations produced by it are simply stipulated by the subject, whereas, since episodic memory requires a causal link with past experience, the identities of the individuals figuring in the representations produced by it may be inherited from the subject's past causal interactions with them, opening up the possibility of error in the latter case but not the former. If we accept that both episodic memory and FMTT are simulational in character, however, this apparent discontinuity may be undermined 
(Michaelian 2016a). On the one hand, since both episodic memory representations and FMTT representations are generated by simulations based on past experience, identities may be inherited from causal interactions in both cases. On the other hand, since both episodic memory representations and FMTT representations are produced by simulations, identities may not be inherited in a straightforward manner, and stipulation by the subject may play a role in both cases. In short, both forms of MTT may sometimes be immune to error through misidentification and sometimes fail to be immune to error through misidentification.

Turning to metaphysical arguments, we saw that discontinuists might argue that past events are constituents of episodic memories, whereas future events are not constituents of episodic future thoughts. There are real worries about how a past event might come to serve as part of a current mental state, but even if we set these aside, the argument encounters a difficulty analogous to one known to afflict direct realism in the philosophy of perception. Direct realists argue that perceived objects are constituents of perceptual states. This forces them to posit a difference in kind between genuine perceptual states and hallucinations, a position known as disjunctivism. Similarly, discontinuists are forced to posit a difference in kind between genuine memories and 'memory hallucinations' - i.e. false memories - and thus to adopt a form of disjunctivism about memory. Disjunctivism is implausible in both instances, because it posits metaphysical differences where there are no corresponding empirical differences: in cases of genuine perception and perceptual hallucination, everything might be the same in neural, cognitive, and phenomenological terms, and the same thing goes for cases of genuine memory and memory hallucination. Discontinuists might insist that the presence of a causal link with a past event, in the case of genuine memory, grounds a metaphysical difference between genuine memory and memory hallucination, but, if remembering is a simulational process, there need be no such link. Moreover, the initial intuitive appeal of direct realism or relationalism is largely undermined by the simulational character of remembering: if there need be no causal link between a memory of a past event and the subject's original experience of it, the claim that the past event is a constituent of the subject's memory of it becomes difficult to motivate.

Discontinuists have also argued that episodic memory involves thinking about particular events, whereas FMTT involves thinking about generic events. Bearing in mind the simulational character of both episodic memory and FMTT, continuists might respond by arguing that, if episodic memory can involve thinking about past events, then so can FMTT and that, if FMTT can involve thinking about generic events, then so can episodic memory (Michaelian 2016a). On the one hand, we might sometimes imagine future events not by imagining generic events and projecting them forwards in time, as discontinuists suggest, but rather by remembering past events and projecting them forwards in time. In such cases, if the memory refers to a particular event, then so, presumably, does the imagination. On the other hand, we might sometimes remember past events by imagining generic events and projecting them backwards in time. In such cases, if the imagination refers to a generic event, then so, presumably, does the memory.

The arguments discussed so far depend indirectly on assumptions about causation, but, as we saw above, discontinuists have also argued more directly that episodic memory and FMTT differ with respect to causation. Focusing on memory, they have argued straightforwardly that a causal link to the represented event is necessary in the case of remembering, in contrast to FMTT, where it is neither necessary nor possible. Here, continuists can reply that, given what we know about the simulational nature of remembering, there can be no guarantee that any given case of remembering involves a causal link to the represented event. Discontinuists are free to insist that only where there is a causal link does genuine remembering occur, but, again, this is to posit a metaphysical difference without a corresponding empirical difference - MTT 
research suggests that remembering involves the same process, regardless of whether a causal link is preserved. The continuist alternative is to treat cases of quasi-memory, for example, not as cases in which the subject merely seems to remember but rather as cases in which the subject genuinely remembers but does so inaccurately. Focusing on FMTT, discontinuists have argued that FMTT involves awareness of the causal openness of the future; episodic memory does not involve a parallel form of awareness, since the past is causally closed. Given the similarity between the simulational processes involved in episodic memory and FMTT, however, continuists can argue that we should expect to find that subjects' judgements about whether they are remembering the past or imagining the future are sometimes mistaken (Michaelian 2016b). Whether subjects do indeed make such mistakes is an empirical question, but, assuming that they do, there will be cases of FMTT which fail to involve awareness of causal openness, as well as cases of episodic memory which involve (mistaken) awareness of causal openness.

An appreciation of the simulational character of remembering likewise grounds continuist responses to arguments for phenomenological discontinuities. Discontinuists have argued that episodic memory, because it refers to actual events, can involve experiential awareness, whereas FMTT, because it does not refer to actual events, cannot. Absent a causal link to the event in question, sustained by the preservation of traces of the subject's experience of the event, the actuality of the event cannot underwrite experiential awareness. Research on constructive memory and MTT demonstrates that, in routine cases, many components of the memory representation are imported from sources other than experience of the remembered event. In such cases, the subject is presumably not experientially aware of all aspects of the event. And the same research suggests that there are cases in which all components of the memory representation are imported from sources other than experience of the remembered event. In such cases, the subject is presumably not experientially aware of any aspect of the event. Discontinuists might argue that genuine remembering occurs only where at least some trace of the original experience is preserved, but, given that similar simulational processes are at work in the full range of cases, it would seem to be preferable to abandon talk of experiential awareness altogether.

In an argument for another sort of phenomenological asymmetry, discontinuists have argued that episodic memory and FMTT are unalike in that only the former necessarily involves autonoetic consciousness. The thought here is that, since episodic memory necessarily concerns experienced events, it may involve autonoetic consciousness as an essential feature; since FMTT might concern either oneself or another, autonoetic consciousness in FMTT must be the outcome of an inferential process. The simulational character of remembering may undermine this alleged disanalogy. If both past-oriented MTT and future-oriented MTT are simulational processes, both might concern either oneself or another. There may be a difference between simulating one's own past experience (i.e. remembering) and simulating the past experience of another, but, if so, there is presumably likewise a difference between simulating one's own future experience and simulating the future experience of another. Autonoetic consciousness might thus be absent in both MTT into the past of another and MTT into the future of another and present in both MTT into one's own past and MTT into one's own future. If it is the outcome of an inferential process in the case of future-oriented MTT, it is presumably the outcome of an inferential process in the case of past-oriented MTT as well.

\section{Conclusion: continuism, discontinuism, and causation}

Ultimately, the debate between continuists and discontinuists seems to boil down to a disagreement over the necessity of causation for episodic memory. If episodic memory, despite 
its simulational character, necessarily involves a causal link to the subject's experience of the remembered event, discontinuism would appear to be the more plausible of the two views. If episodic memory does not necessarily involve a causal link to the subject's experience of the remembered event, continuism may carry the day.

MTT research, we have seen, does suggest that remembering need not involve the preservation of traces of the subject's experience of the remembered event. But this might not be enough to undermine the claim that remembering necessarily involves a causal link to the subject's experience of the remembered event. Standard versions of the causal theory assume that appropriate causal links are sustained by the preservation of traces of experience, but there are alternatives to this version of the theory. Attributionalist accounts of memory, in particular, favour a procedural characterization of the causal links involved in remembering (Jacoby et al. 1989; Mitchell and Johnson 2000; Addis et al. 2009), claiming that the detection of procedural properties (such as fluency) of subpersonal processes triggers attribution to past experience. Such properties, in turn, reflect past experience, so, if attributionalism is right, episodic memory would result from the monitoring of a procedural effect of past experience. Attributionalism has considerable advantages. It allows us to preserve the distinction between remembering and merely imagining the past which is abandoned by simulationist approaches, since fluency can trigger attribution to past experience even when it is due to other causes. And it can explain the observation that greater neural activity is observed in FMTT than in episodic memory, since the simulation involved in episodic memory will in general be more fluent, due to the effect of past experience, than that involved in FMTT. But its main import, in the present context, is that it promises to identify a causal difference between episodic memory and FMTT, which may in turn sustain the various epistemological, metaphysical, and phenomenological differences for which discontinuists argue.

Whether attributionalism can ultimately fulfil this promise remains to be seen. Attributionalism may secure a causal difference between episodic memory and FMTT without securing a difference sufficient to sustain the qualitative differences that discontinuists posit. And it may yet turn out that attributionalism does not in fact secure a causal difference between episodic memory and FMTT. In essence, attributionalism says that representations resulting from more fluent simulations tend to be attributed to past experience. Fluency, in turn, is typically an effect of past experience. Thus, in cases where the subject takes himself to be remembering, there will usually be a causal link with past experience. There is, however, no guarantee of such a link, since fluency may result from other causes. When it does, discontinuists must claim that the subject merely seems to remember, on penalty of admitting that a causal link is not in fact necessary for remembering. Continuists, however, will respond that this claim is unmotivated: if the same simulational process unfolds in two cases, and if both cases are characterized by the same level of fluency, both should be categorized as cases of remembering. In the final analysis, then, the continuist-discontinuist debate may bottom out in a clash of intuitions over the necessity of causation for remembering.

\section{Notes}

1 Psychologists have tended to favour continuism, whereas philosophers have tended to favour discontinuism. But the theoretical divide need not align with the disciplinary border, and some psychologists remain sceptical of the evidence for continuism (e.g. Friedman 2007; Klein and Steindam 2016), while some philosophers have developed continuist analyses that classify episodic memory and FMTT alike as forms of imagination (Hopkins 2014; Michaelian 2016b).

2 See Suddendorf and Corballis (2007), and Szpunar (2010) for further detail. 
3 Compare, e.g. the self-projection approach (Buckner and Carroll 2007) and the scene construction approach (Hassabis and Maguire 2009).

4 There is a debate among philosophers as to whether episodic memories are immune to error through misidentification or not. Evans (1982) and Hamilton (2007) answer in the affirmative, while Shoemaker (1970) and Coliva (2006) maintain this is only a contingent feature of remembering. Our take here is closer to the latter, which we cannot argue for here for reason of space.

\section{Related topics}

- Taxonomy and unity of memory

- $\quad$ Phenomenology of remembering

- Memory causation

- Intentional objects of memory

- Memory and consciousness

- Memory and imagination

- $\quad$ Frederic Bartlett

\section{Further reading}

For an introduction to mental time travel, see Chapter 6 of Michaelian, K. 2016b. Mental Time Travel: Episodic Memory and Our Knowledge of the Personal Past. Cambridge, MA: MIT Press.

\section{References}

Addis, D. R., R. P. Roberts, and D. L. Schacter (2011) Age-related neural changes in autobiographical remembering and imagining. Neuropsychologia 49(13): 3656-69.

Addis, D. R., A. T. Wong, and D. L. Schacter (2007) Remembering the past and imagining the future: Common and distinct neural substrates during event construction and elaboration. Neuropsychologia 45(7): 1363-77.

Addis, D. R., R. Musicaro, L. Pan, and D. L. Schacter (2010) Episodic simulation of past and future events in older adults: Evidence from an experimental recombination task. Psychology and Aging 25(2): 369-76.

Addis, D. R., L. Pan, M.-A. Vu, N. Laiser, and D. L. Schacter (2009) Constructive episodic simulation of the future and the past: Distinct subsystems of a core brain network mediate imagining and remembering. Neuropsychologia 47(11): 2222-38.

Atance, C. M. (2008) Future thinking in young children. Current Directions in Psychological Science 17(4): 295-8.

Bartlett, F. C. (1932) Remembering: A Study in Experimental and Social Psychology. Cambridge: Cambridge University Press.

Bernecker, S. (2010) Memory: A Philosophical Study. New York: Oxford University Press.

Berntsen, D. and A. Bohn (2010) Remembering and forecasting: The relation. Memory \& Cognition 38(3): 265-78.

Berryhill, M. E., L. Picasso, R. Arnold, D. Drowos, and I. R. Olson (2010) Similarities and differences between parietal and frontal patients in autobiographical and constructed experience tasks. Neuropsychologia 48(5): 1385-93.

Brewer, W. F. (1996) What is recollective memory? Remembering Our Past: Studies in Autobiographical Memory. Ed. D. C. Rubin. Cambridge: Cambridge University Press.

Buckner, R. and D. Carroll (2007) Self-projection and the brain. Trends in Cognitive Sciences 11(2): $49-57$.

Campbell, J. (2002) Reference and Consciousness. New York: Oxford University Press.

Coliva, A. (2006) Error through misidentification: Some varieties. Journal of Philosophy 103(8): 403-25.

D'Argembeau, A. and M. Van der Linden (2004) Phenomenal characteristics associated with projecting oneself back into the past and forward into the future: Influence of valence and temporal distance. Consciousness and Cognition 13(4): 844-58.

D'Argembeau, A. and M. Van der Linden (2006) Individual differences in the phenomenology of mental time travel: The effect of vivid visual imagery and emotion regulation strategies. Consciousness and Cognition 15(2): 342-50. 
D’Argembeau, A., O. Renaud, and M. Van der Linden (2011) Frequency, characteristics and functions of future-oriented thoughts in daily life. Applied Cognitive Psychology 25(1): 96-103.

De Brigard, F. and K. S. Giovanello (2012) Influence of outcome valence in the subjective experience of episodic past, future, and counterfactual thinking. Consciousness and Cognition 21(3): 1085-96.

Debus, D. (2008) Experiencing the past: A relational account of recollective memory. Dialectica 62(4): 405-32.

Debus, D. (2013) Thinking about the past and experiencing the past. Mind \& Language 28(1): 20-54.

Debus, D. (2014) 'Mental time travel': Remembering the past, imagining the future, and the particularity of events. Review of Philosophy and Psychology 5(3): 333-50.

Debus, D. (2016) Temporal perspectives in imagination: On the nature and value of imagining the future. Seeing the Future: Theoretical Perspectives on Future-Oriented Mental Time Travel. Eds. K. Michaelian, S. B. Klein, and K. K. Szpunar. New York: Oxford University Press.

Duval, C., B. Desgranges, V. de La Sayette, S. Belliard, F. Eustache, and P. Piolino (2012) What happens to personal identity when semantic knowledge degrades? A study of the self and autobiographical memory in semantic dementia. Neuropsychologia 50(2): 254-65.

Evans, G. (1982) The Varieties of Reference. New York: Oxford University Press.

Friedman, W. J. (2007) The meaning of time in episodic memory and mental time travel. Behavioral and Brain Sciences 30(June): 323.

Hamilton, A. (2007) Memory and self-consciousness: Immunity to error through misidentification. Synthese 171: 409-17.

Hassabis, D. and E. A. Maguire (2009) The construction system of the brain. Philosophical Transactions of the Royal Society B: Biological Sciences 364(1521): 1263-71.

Hassabis, D., D. Kumaran, S. D. Vann, and E. A. Maguire (2007) Patients with hippocampal amnesia cannot imagine new experiences. Proceedings of the National Academy of Sciences 104(5): 1726-31.

Hopkins, R. (2014) Episodic memory as representing the past to oneself. Review of Philosophy and Psychology 5(3): 313-31.

Irish, M., D. R. Addis, J. R. Hodges, and O. Piguet (2012) Considering the role of semantic memory in episodic future thinking: Evidence from semantic dementia. Brain 135(7): 2178-91.

Jacoby, L. L., C. M. Kelley, and J. Dywan (1989) Memory attributions. Varieties of Memory and Consciousness: Essays in Honour of Endel Tulving. Eds. H. L. Roediger and F. I. M. Craik. Hillsdale, NJ: Lawrence Erlbaum.

Klein, S. B. (2016) Autonoetic consciousness: Reconsidering the role of episodic memory in futureoriented self-projection. Quarterly Journal of Experimental Psychology 69(2): 381-401.

Klein, S. B. and C. Steindam (2016) The role of subjective temporality in future-oriented mental time travel. Seeing the Future: Theoretical Perspectives on Future-Oriented Mental Time Travel. Eds. K. Michaelian, S. B. Klein, and K. K. Szpunar. New York: Oxford University Press.

Klein, S. B., J. Loftus, and J. F. Kihlstrom (2002) Memory and temporal experience: The effects of episodic memory loss on an amnesic patient's ability to remember the past and imagine the future. Social Cognition 20(5): 353-79.

McDonough, I. and D. Gallo (2010) Separating past and future autobiographical events in memory: Evidence for a reality monitoring asymmetry. Memory \& Cognition 38(1): 3-12.

Martin, C. B. and M. Deutscher (1966) Remembering. Philosophical Review 75(2): 161-96.

Martin, M. G. F. (2001) Out of the past: Episodic recall as retained acquaintance. Time and Memory: Issues in Philosophy and Psychology. Eds. C. Hoerl and T. McCormack. New York: Oxford University Press.

Martin, V. C., D. L. Schacter, M. C. Corballis, and D. R. Addis (2011) A role for the hippocampus in encoding simulations of future events. Proceedings of the National Academy of Sciences 108(33): 13858-63.

Michaelian, K. (2016a) Against discontinuism: Mental time travel and our knowledge of past and future events. Seeing the Future: Theoretical Perspectives on Future-Oriented Mental Time Travel. Eds. K. Michaelian, S. B. Klein, and K. K. Szpunar. New York: Oxford University Press.

Michaelian, K. (2016b) Mental Time Travel: Episodic Memory and Our Knowledge of the Personal Past. Cambridge, MA: MIT Press.

Michaelian, K., S. B. Klein, and K. K. Szpunar (2016) The past, the present, and the future of futureoriented mental time travel. Seeing the Future: Theoretical Perspectives on Future-Oriented Mental Time Travel. Eds. K. Michaelian, S. B. Klein, and K. K. Szpunar. New York: Oxford University Press.

Mitchell, K. J. and M. K. Johnson (2000) The Oxford Handbook of Memory. Eds. E. Tulving and F. I. M. Craik. New York: Oxford University Press. 
Perner, J., D. Kloo, and M. Rohwer (2010) Retro- and prospection for mental time travel: Emergence of episodic remembering and mental rotation in 5- to 8-year-old children. Consciousness and Cognition 19(3): 802-15.

Perrin, D. (2016) Asymmetries in subjective time. Seeing the Future: Theoretical Perspectives on Future-Oriented Mental Time Travel. Eds. K. Michaelian, S. B. Klein, and K. K. Szpunar. New York: Oxford University Press.

Rasmussen, A. and D. Berntsen (2013) The reality of the past versus the ideality of the future: Emotional valence and functional differences between past and future mental time travel. Memory \& Cognition 41(2): 187-200.

Rathbone, C. J., M. A. Conway, and C. J. A. Moulin (2011) Remembering and imagining: The role of the self. Consciousness and Cognition 20(4): 1175-82.

Recanati, F. (1993) Direct Reference: From Language to Thought. Oxford: Blackwell.

Recanati, F. (2007) Perspectival Thought: A Plea for (Moderate) Relativism. New York: Clarendon Press.

Rosenbaum, R. S., S. Köhler, D. L. Schacter, M. Moscovitch, R. Westmacott, S. E. Black, F. Gao, and E. Tulving (2005) The case of K.C.: Contributions of a memory-impaired person to memory theory. Neuropsychologia 43(7): 989-1021.

Schacter, D. L. and D. R. Addis (2007a) The cognitive neuroscience of constructive memory: Remembering the past and imagining the future. Philosophical Transactions of the Royal Society B: Biological Sciences 362(1481): 773-86.

Schacter, D. L. and D. R. Addis (2007b) Constructive memory: The ghosts of past and future. Nature 445(7123): 27.

Schacter, D. L., D. R. Addis, and R. L. Buckner (2007) Remembering the past to imagine the future: The prospective brain. Nature Reviews Neuroscience 8(9): 657-61.

Schacter, D. L., D. R. Addis, D. Hassabis, V. C. Martin, R. N. Spreng, and K. K. Szpunar (2012) The future of memory: Remembering, imagining, and the brain. Neuron 76(4): 677-94.

Shanton, K. and A. Goldman (2010) Simulation theory. Wiley Interdisciplinary Reviews: Cognitive Science 1(4): $527-38$.

Shao, Y., X. Yao, S. J. Ceci, and Q. Wang (2010) Does the self drive mental time travel? Memory 18(8): 855-62.

Shoemaker, S. (1970) Persons and their pasts. American Philosophical Quarterly 7(4): 269-85.

Storm, B. C. and T. A. Jobe (2012) Remembering the past and imagining the future: Examining the consequences of mental time travel on memory. Memory 20(3): 224-35.

Suddendorf, T. (2010) Episodic memory versus episodic foresight: Similarities and differences. Wiley Interdisciplinary Reviews: Cognitive Science 1(1): 99-107.

Suddendorf, T. and J. Busby (2005) Making decisions with the future in mind: Developmental and comparative identification of mental time travel. Learning and Motivation 36(2): 110-25.

Suddendorf, T. and M. C. Corballis (2007) The evolution of foresight: What is mental time travel, and is it unique to humans? Behavioral and Brain Sciences 30(03): 299-313.

Szpunar, K. K. (2010) Episodic future thought: An emerging concept. Perspectives on Psychological Science 5(2): 142-62.

Szpunar, K. K., J. M. Watson, and K. B. McDermott (2007) Neural substrates of envisioning the future. Proceedings of the National Academy of Sciences 104(2): 642-7.

Tulving, E. (1972) Episodic and semantic memory. Organization of Memory. Eds. E. Tulving and W. Donaldson, pp. 381-402. New York: Academic Press.

Tulving, E. (1985) Elements of Episodic Memory. New York: Oxford University Press.

Tulving, E. (2002) Episodic memory: From mind to brain. Annual Review of Psychology 53(1): 1-25.

Viard, A., B. Desgranges, F. Eustache, and P. Piolino (2012) Factors affecting medial temporal lobe engagement for past and future episodic events: An ALE meta-analysis of neuroimaging studies. Brain and Cognition 80(1): 111-25.

Wagoner, B. (2016) The Constructive Mind: Frederic Bartlett's Psychology in Reconstruction. Cambridge: Cambridge University Press.

Williams, N. Ellis, C. Tyers, H. Healy, G. Rose, and A. Macleod (1996) The specificity of autobiographical memory and imageability of the future. Memory \& Cognition 24(1): 116-25. 